\title{
Transsphenoidal surgery in Cushing disease: The challenging microadenoma (Local experience)
}




\title{
Transsphenoidal surgery in Cushing disease: The challenging microadenoma (Local experience)
}

\author{
Wael K. Zakaria, Ahmed N. Taha \\ Department of Neurosurgery, Mansoura University Hospital, Mansoura, EGYPT
}

\begin{abstract}
Background: Cushing disease is uncommon challenging disease. The adenomas are usually small in size in most case making the disease diagnosis and management is sometimes difficult. In some cases, the tumor cannot be identified on imaging studies and in many cases the adenoma is eccentric in location adding more difficulties to the trans-sphenoid approach for excision of such tricky tumors. Object: to evaluate the challenge of diagnosis and trans-sphenoid surgery for ACTH pituitary microadenomas. Methods: 21 patients with ACTH secreting adenomas were involved in this retrospective study. All cases were operated up on via trans-sphenoid approach during the period from January 2009 till October 2015. All of them were microadenomas. All patients had obvious Cushing manifestations. In all cases magnetic resonance (MR) imaging and CT paranasal sinuses were performed. In this study: cases with macroadenomas and recurrent cases after previous trans-sphenoid approach or gamma knife radiosurgery were excluded. Results: Among the 21 patients; 14 were female and 7 weremale with age ranging from 21 to 44 years. The imaging study was positive for microadenoma in 18 patients while in 3 cases; no tumor was seen on the MRI imaging. All were operated via the trans-sphenoid approach (12 patients via the microscopic technique and other 9 patients via the endoscopic technique). The adenoma was successfully removed in 15 out of the 18 patients with evident adenoma on pre-operative MRI imaging while partial hypophysectomy were done in 5 cases without an evident adenoma on pre-operative MRI study or difficult adenoma identification. In one patient; the procedure was aborted because of sphenoid sinus abnormalities and the tumor was successfully removed via trans-cranial approach. Disease remission was achieved in 17 patients. In 4 patients; complete remission was not achieved and gamma knife radiosurgery was done after surgery. Disease progression occurred in two patients with initial remission and was treated gamma knife radiosurgery. 13 patients had an ACTH deficiency after surgery while other hormonal replacement therapy is needed in only 5 cases. CSF rhinorrhea occurred in 2 patients and was managed with transient lumbar drain without any subsequent morbidities. Transient diabetes insipidus occurred in 6
\end{abstract}


cases and was treated conservatively. Conclusions: The transsphenoidal approach ACTH secreting pituitary microadenomas is considered safe and effective for achieving disease remission despite the challenge of diagnosis and intra-operative tumor identification.

Key words: Adrenocorticotrophic hormone, Magnetic resonance, Computed tomography, Cerebrospinal fluid

\section{Introduction}

Surgery is considered the golden standard treatment for ACTH secreting adenomas causing Cushing disease. These benign adenomas are mostly microadenoma and easily achievable via the classic trans-sphenoid approach. However, there is still considerable challenges in the disease diagnosis management. In many cases (around 40\%), the tumor cannot be identified on the preoperative imaging studies (post-contrast magnetic resonance imaging) and intraoperative identification of the adenoma is dependent on the experience of the surgeon. Even if the inferior petrosal sinus sampling is feasible; its accuracy in identification the site of the adenoma is questionable. ${ }^{1{ }^{2}, 9}$ Another challenge is eccentric location of many adenomas is eccentric and despite its small size; it can be very close the carotid artery adding more difficulties to the trans-sphenoid approach for excision of such tricky tumors. ${ }^{57} \cdot 10$ The goal of surgery shouldn't only to remove the tumor but also to preserve the pituitary function to prevent postoperative hypopituitarism necessitating long term hormonal replacement therapy. ${ }^{3,4,5,8}$ The aim of this study is to evaluate the challenge of diagnosis and potential difficulties and outcome of the trans-sphenoid approach for ACTH secreting pituitary adenomas.

\section{Patients and methods}

21 patients with ACTH secreting adenomas were involved in this retrospective study. All the patient had obvious clinical manifestations of Cushing disease. All these cases were operated up on in the neurosurgery department via the trans-sphenoidal approach during the period from January 2009 to October 2015.

We evaluated all the medical data and imaging studies to assess all the potential difficulties in the disease diagnosis and the expected surgical challenge and this data was correlated with the operative finding and postoperative outcome particularly the rate of disease remission. Data analysis included patient age, gender, clinical manifestations, pre-operative and initial and late postoperative hormonal levels including serum cortisol and ACTH levels and pre-operative and post-operative imaging studies. In all cases, magnetic resonance (MR) imaging of the sellar region and CT paranasal sinuses were performed. In this study; cases with macroadenomas (greater than one CM in the size) and recurrent cases after previous transsphenoid approach or gamma knife radiosurgery were excluded. Outcome assessment was evaluated by improvement of the Cushing manifestation, hormonal assessment to ensure biochemical remission and post-operative contrast enhancing magnetic resonance imaging. Post-operative cortisol level evaluation was routinely done on 
the first day after the surgery and then after one, three and six months thereafter. Then hormonal evaluation was done annually for assessment of any relapse. Remission was defined by either normalization of the serum cortisol level or those with low serum cortisol level $(\leq 3 \mathrm{mg} / \mathrm{dl})$ necessitating hormonal replacement therapy. Those patients with remaining elevated serum cortisol level were considered treatment failure. Post-operative imaging (MRI) was done initially after three months to ensure any residual tumor and then annually for five years to detect any recurrence. Post-operative morbidities (transient or permanent) were also analyzed.

\section{Results}

Among the 21 patients; 14 were females and 7 were males with age ranging from 21 to 44 years (mean 33.6). All patients had the clinical manifestation of Cushing disease (Table 1). Headache was manifest in eleven patients, 2 patients had ocular palsy concomitant with his Cushing manifestation (Figure 1), and in one patient; impotence was his early presentation for Cushing disease. In three patients; uncontrolled diabetes was the triggering for the diagnosis of the disease and in one patient refractory hypertension was the initial presentation. Depending on the preoperative post-contrast magnetic resonance study; we have 2 categories of patients; those with positive microadenoma (18 patients) and those with negative finding ( 3 patients). All patients were operated up on via the transsphenoid approach (12 patients via the microscopic endonasal technique and other 9 patients via the endoscopic endonasal technique) (Table 2). The technique was exactly like what was widely described in the literature but we have faced with difficulties from mucosal changes rendering it more friable and bloody and difficulties from difficult control of the blood pressure. In one patient with conical shaped sinus; drilling of the bony sinus was performed under image guidance but bleeding was evident and the approach was aborted and the adenoma was removed three weeks later via the trans-cranial approach.

TABLE I

Patients characteristics

\begin{tabular}{|l|l|}
\hline Patient sex & Male 7 \\
& Female 14 \\
& Male-female ratio: 1:2 \\
\hline Age & 21 to 44 years (mean 33.6) \\
\hline Clinical presentation & Headache: 11 patients \\
(Cushing manifestation) & Diabetes: 12 patients \\
& (Three of them was the initial presentation) \\
& Hypertension:13 patients \\
(One of them was the initial presentation) & Skin changes: 19 patients \\
& Abnormal fat distribution: 18 patients \\
& Impotence: 1 patients \\
\hline Follow up period & 9 months - 78 months \\
\hline
\end{tabular}




\section{TABLE II}

Imaging characteristic, Treatment plan and outcome of surgery

\begin{tabular}{|c|c|}
\hline Pre-operative MRI of the sella & $\begin{array}{l}\text { Positive for adenoma: } 18 \text { patients } \\
\text { Negative for adenoma: } 3 \text { patients }\end{array}$ \\
\hline Technique of surgery & $\begin{array}{l}\text { Microscopic trans-sphenoidal approach: } 12 \text { patients } \\
\text { Endoscopic trans-sphenoidal approach: } 9 \text { patients }\end{array}$ \\
\hline Intra-operative finding & $\begin{array}{l}\text { Adenoma removal: } \\
15 \text { via the trans-sphenoidal approach } \\
\text { One via additional trans-cranial approach after aborted Tans-sphenoid } \\
\text { approach } \\
\text { Partial hypophysectomy: } 5 \text { patients }\end{array}$ \\
\hline $\begin{array}{l}\text { Pathological confirmation of } \\
\text { adenoma }\end{array}$ & $\begin{array}{l}\text { Positive: } 18 \text { patients } \\
\text { Negative: } 3 \text { patients }\end{array}$ \\
\hline Post-operative treatment & $\begin{array}{l}\text { Gamma knife radiosurgery: } 6 \text { patients } \\
4 \text { patients: treatment failure } \\
2 \text { patients: disease progression after initial remission } \\
\text { Medical treatment: } \\
\text { Cortisol replacement therapy: } 13 \text { patients } \\
\text { Other hormonal replacement therapy: } 5 \text { patients }\end{array}$ \\
\hline Surgery related morbidities & $\begin{array}{l}\text { CSF rhinorrhea: } 3 \text { patients (Transient) } \\
\text { Transient diabetes insipidus: } 6 \text { patients }\end{array}$ \\
\hline
\end{tabular}

\section{TABLE III}

Disease remission (Biochemical markers)

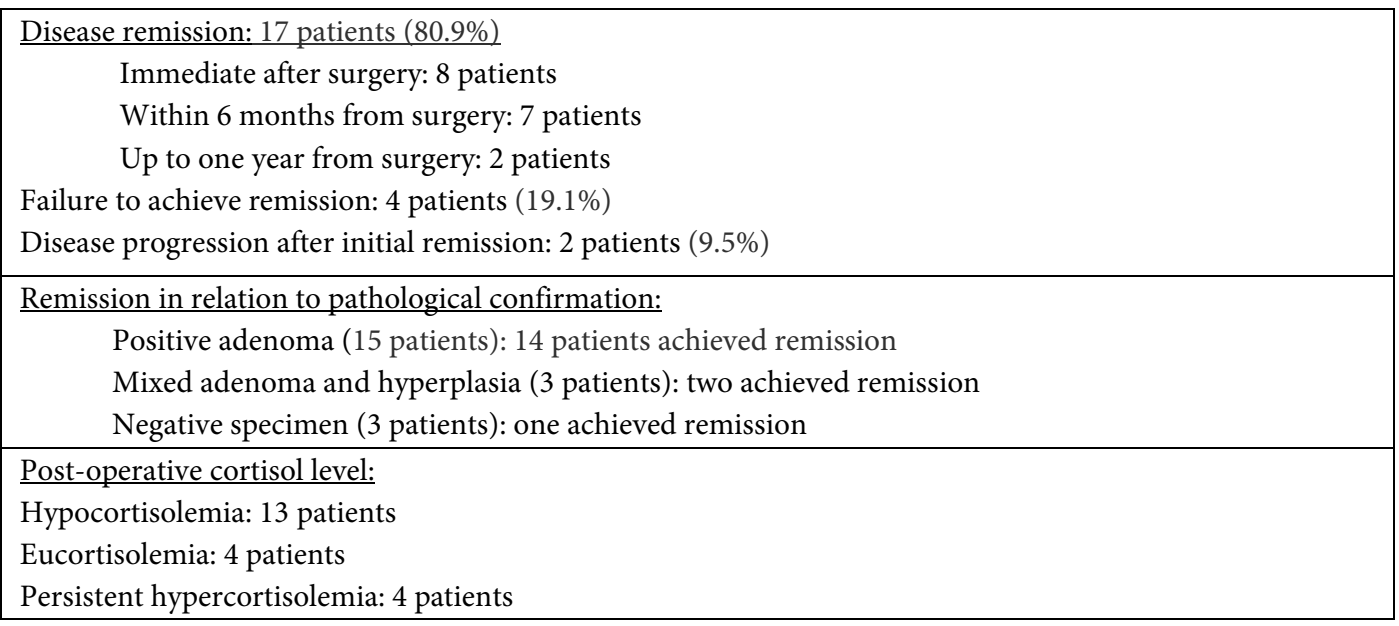


The adenoma was successfully removed in 15 out of the 18 patients with evident adenoma on pre-operative post-contrast magnetic resonance study (Figure 2) while partial hypophysectomy were done in 5 cases without an evident adenoma on pre-operative MRI study or difficult adenoma identification. Pathological confirmation for the adenoma was achieved in 15 patients, mixed adenoma and hyperplasia in 3 patients while specimen was negative in three cases. Follow up period ranged from 9 months up to 78 months. Disease remission (Table 3) was achieved in 17 patients (80.9\%). In 4 patients (19.1\%); complete remission was not achieved and gamma knife radiosurgery was done after surgery. Disease progression occurred in two patients $(9.5 \%)$ after initial remission and was treated with gamma knife radiosurgery.

No approach related mortalities occurred. 13 patients had post-operative cortisol deficiency and was maintained on replacement therapy. Other hormonal replacement therapy was needed in only 5 cases. CSF rhinorrhea occurred in 2 patients and was managed with transient lumbar drain without any subsequent morbidities. Also, the case that was operated via the trans-cranial approach after failed trans-sphenoid surgery developed CSF rhinorrhea after 2nd surgery and was managed with transient lumbar drain. Transient diabetes insipidus occurred in 6 cases and was treated conservatively.

\section{Discussion}

Cushing disease is uncommon challenging disease. It occurs due to ACTH secreting adenomas which in majority of cases are microadenomas but many reports showed that macroadenomas can cause up to $13 \%$ of Cushing disease patients. ${ }^{6 / 8}, 9,11,13,14$ However, we decided to concentrate in this reports on challenge and outcome of surgery for de novo cases of ACTH secreting adenomas rather than macroadenomas or previously treated cases to stress on the challenge of treatment and outcome of such small lesion not to involve other potential challenge rather than the adenoma itself. ${ }^{1,3,6,11,12}$

The female predominance and age distribution in our study matches with the finding of other reports. ${ }^{12,5,7,9}$ The challenge of this disease starts with disease diagnosis. Several factors are important in the endeavor to obtain satisfactory results. Preoperative detection of the ACTH secreting adenoma is crucial for the surgical outcome, achievement of cure and prevention of surgically induced hypopituitarism. ${ }^{8,10,15,16,17}$ Our 1st problem was with three cases (14.3\%) with all manifestation of Cushing disease with exclusion with all potential differential diagnosis with negative finding of the postcontrast magnetic resonance of the sella. Our incidence of negative imaging is lower than what reported in other studies which may reach up to $40 \%$ of Cushing microadenomas which mostly due to lack of referral of MRI negative patients to our neurosurgical

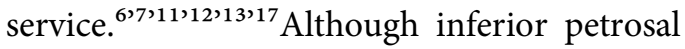
sampling played a role in identification the site of adenoma however we don't have such facility and in many reports, its accuracy is up to $60 \%$ in identification the site of adenoma. ${ }^{3,4,9,10,11}$ In such cases our decision was to explore the pituitary gland for the adenoma or do partial hypophysectomy. 
The trans-sphenoid technique is exactly like what have been reported in different series and there was no difference between the microscopic versus the endoscopic approach for addressing such tiny adenomas. ${ }^{12,5}, 8,16 \times 17$ However, in our cases there was a potential challenge in the approach specific to this problem in the form of friable bloody nasal mucosa adding some difficulties to the nasal step of the approach. Another problem was the difficult control of the blood pressure during the procedure that increased the bleeding during the nasal phase of the approach. In one case; the sphenoid sinus was conical shaped type and under $\mathrm{C}$ arm guidance we tried to drill the bony sinus to reach the sellar floor but due to excessive bleeding and lack of navigation system under our facilities; we decided to abort the procedure and to come back from above via trans-cranial approach and the adenoma was removed. In five patients, no adenoma could be identified during pituitary gland exploration and partial hypophysectomy was performed. Many reports addressed the issue of negative exploration of pituitary gland for adenoma and advocated hemi-hypophysectomy of pituitary gland particularly on the side of positive inferior petrosal sampling with reported cases of disease remission even with absence of any pathological confirmation. ${ }^{6,9} \cdot 10 \cdot 11,14,17$

The issue of Cushing disease remission both clinically and by biological confirmation has been addressed in many reports with overall remission ranging from 59 to $98 \%$ in different

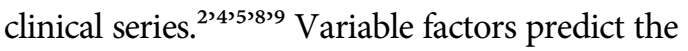
potential remission rate; the size of adenoma, whether its de novo or recurrent, presence of cavernous sinus invasion and presence or absence of pathological confirmation. Remission rate is higher in newly diagnosed microadenomas without cavernous sinus invasion and slightly higher in pathologically proven adenoma rather than those with inconclusive pathological smear. ${ }^{12277^{2}} 2^{2} 13,14 \mathrm{We}$ have achieved remission in $80.9 \%$ of cases but all of them is microadenomas. In one case; the adenoma was located laterally in close contact with internal carotid artery and despite pathological confirmation of being adenoma; remission wasn't achieved and was sent for gamma knife (Figure 1). Among our three cases with negative pathological confirmation; only one case (33.3\%) showed disease remission and other two cases were sent for gamma knife.

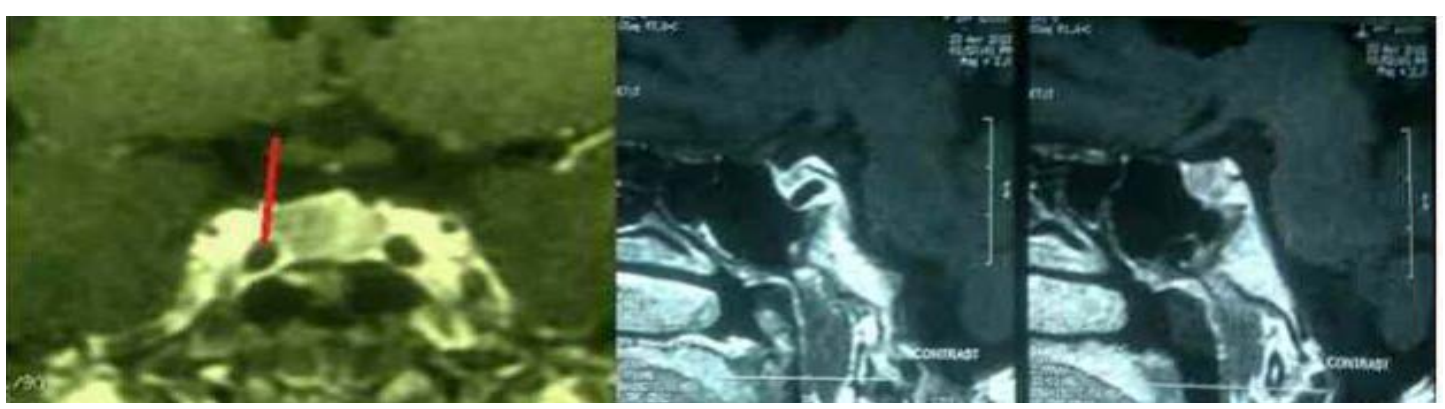

Figure 1 - MRI images of case with Cushing disease with uncontrolled diabetes presented with ptosis due to $3^{\text {rd }}$ nerve palsy 

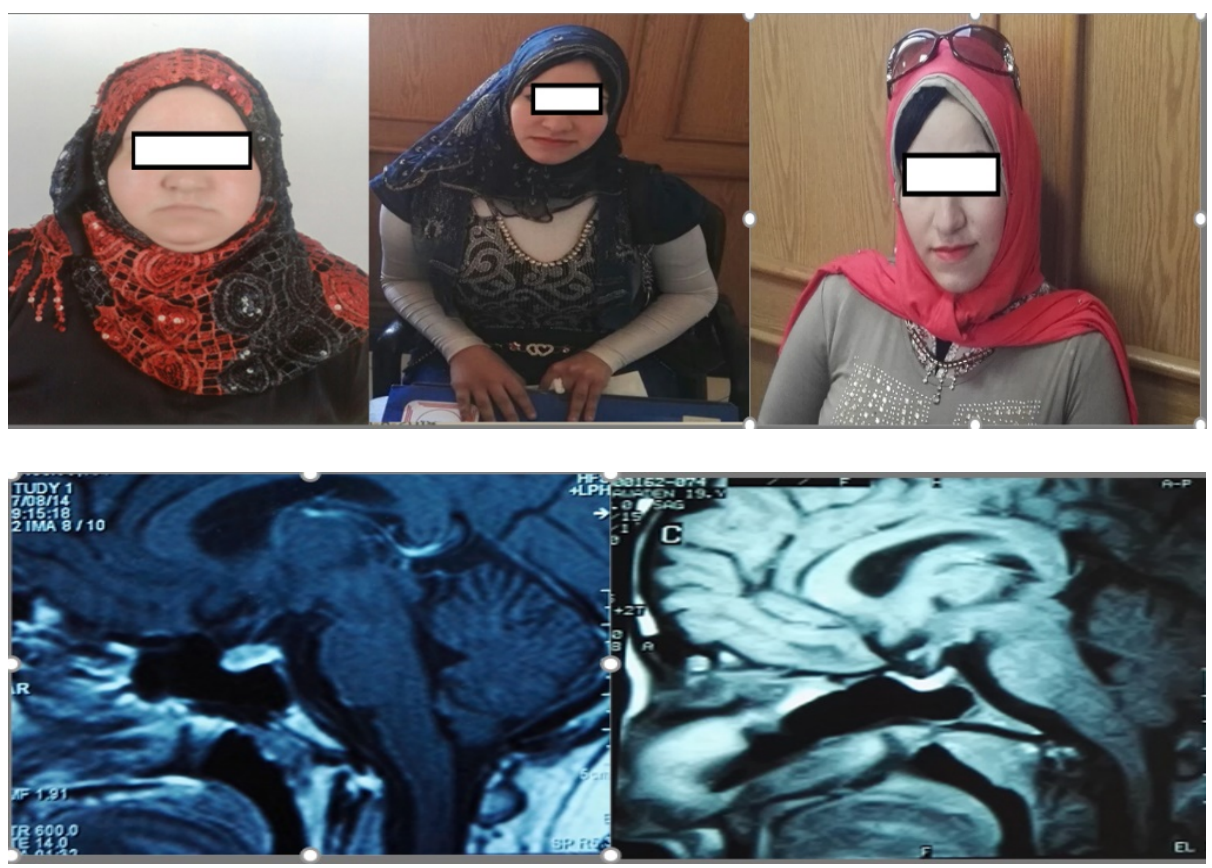

Figure 2 - A case of Cushing disease removed via microscopic trans-sphenoid approach. The above image showed her pre-operative picture and that one and three years after surgery with regression of all Cushing manifestations and the below image showed her pre-operative and post-operative MRI with total removal of her adenoma

In another case that post-operative remission wasn't achieved; the pathological smear revealed mixed adenoma and hyperplasia and the patient was also referred for gamma knife treatment.

Recurrence of disease is not uncommon and it can happen over many years after initial remission hence long term follow up is necessary for those patients. Overall recurrence rate ranged from $5 \%$ to $60 \%$ in many case series and it can occur up to 10 years from remission. ${ }^{9{ }^{\prime} 0^{\prime 11}{ }^{1} 13{ }^{114}}$ Recurrence is more expected in cases of macroadenomas, cavernous sinus invasion and with negative pathological confirmations or when the hyperplasia rather than adenoma is the cause of the disease. ${ }^{23^{3} / 4817}$ In our cases; we have two cases $(9.5 \%)$ of disease progression after initial remission. The pathology in one of them was mixed adenoma and hyperplasia and was advised to have gamma knife treatment. The 2nd case showed recurrent adenoma on postoperative magnetic resonance study but the patient preferred to do gamma knife radiosurgery rather than the advised repeated trans-sphenoid approach. Complication after trans-sphenoid surgery for Cushing disease is relatively high compared to other pituitary adenomas and it may reach up to $53 \%$ in some reports. ${ }^{49} \cdot 1115$ Also, mortality rate has been reported up to $8.4 \%$. Complications could be minor and transient or it may be permeant or even life threatening. Reported morbidities 
included Epistaxis, pituitary hypofunction, CSF leakage, pneuomocephalus, meningitis, visual impairment, ocular motility dysfunction, and occasional deep venous thrombosis and pulmonary embolism. ${ }^{56,778,14,16,17}$ Some reports ${ }^{9,10^{\prime}, 11,12,13}$ claimed that morbidity was less with endoscopic procedures rather than with microscopic technique but in our study; there was no much difference. Our reported morbidities included transient CSF rhinorrhea (2 patients), transient diabetes insipidus (6 cases) and hypopituitarism (5 patients). Another case that was operated via the transcranial approach after failed trans-sphenoid surgery developed CSF rhinorrhea after 2nd surgery and was managed with transient lumbar drain. 13 patients had post-operative cortisol deficiency and was maintained on replacement therapy.

\section{Conclusions}

The transsphenoidal approach for ACTH secreting pituitary microadenomas is considered safe and effective for achieving disease remission despite the challenge of diagnosis and intra-operative tumor identification. Both microscopic and endoscopic techniques are of equal safety and efficacy. Both pre-operative tumor identification on magnetic resonance imaging of the sella and positive pathological confirmation of removed tissue play a role in achievement of remission. Disease progression may occur after initial remission hence long term follow up of those patients is necessary.
Correspondence

Wael K. Zakaria

Department of Neurosurgery, Mansoura University

Hospital, Gomhorria Str., Mansoura, Egypt

Phone: +2 01229333344

E-mail:drwaelmusa@yahoo.com

drwaelmusa@gmail.com

\section{References}

1. Atkinson AB, Kennedy A, Wiggam MI, McCance DR, Sheridan B: Long-term remission rates after pituitary surgery for Cushing's disease: the need for long-term surveillance. Clin Endocrinol (Oxf) 63:549-559, 2005

2. Cappabianca P1, Cavallo LM, Colao A, de Divitiis E.:Surgical complication associated with the endoscopic endonasal trans-sphenoidal approach for pituitary adenomas. J Neurosurg. Aug 97(2):293-298,2002

3. Chandler WF, Barkan AL, Hollon T, Sakharova A, Sack J, Brahma B, Schteingart DE: Outcome of Transsphenoidal Surgery for Cushing Disease: A SingleCenter Experience Over 32 Years. Neurosurgery. Feb 78(2):216-223, 2016

4. Chee GH, Mathias DB, James RA, Kendall-Taylor P: Transsphenoidal pituitary surgery in Cushing's disease: Can we predict outcome?. Clin Endocrinol (Oxf) 54:617626, 2001

5. Dehdashti AR1, Gentili F.: Current state of the art in the diagnosis and surgical treatment of Cushing disease: early experience with a purely endoscopic endonasal technique. Neurosurg Focus. 23(3): E9, 2007

6. Hassan-Smith ZK1, Sherlock M, Reulen RC, Arlt W, Ayuk J, Toogood AA, Cooper MS, Johnson AP, Stewart PM.: Outcome of Cushing's disease following transsphenoidal surgery in a single center over 20 years. J Clin Endocrinol Metab. Apr;97(4):1194-1201, 2012

7. Jagannathan J, Sheehan JP, Jane JA Jr.: Evaluation and management of Cushing syndrome in cases of negative sellar magnetic resonance imaging. Neurosurg Focus: 23(3): E3, 2007

8. Netea-Maier RT, van Lindert EJ, den Heijer M, van der Eerden A, Pieters GF, Sweep CG, et al: Transsphenoida pituitary surgery via the endoscopic technique: results in 35 consecutive patients with Cushing's disease. Eur J Endocrinol 154:675-684, 2006 
9. Patil CG, Veeravagu A, Prevedello DM, Katznelson L, Vance ML, Laws ER Jr.: Outcomes after repeat transsphenoidal surgery for recurrent Cushing's disease. Neurosurgery: 63(2):266-270, 2008

10. Pouratian N, Prevedello DM, Jagannathan J, Lopes MB, Vance ML, Laws ER Jr: Outcomes and management of patients with Cushing's disease without pathological confirmation of tumor resection after transsphenoidal surgery. J Clin Endocrinol Metab 92:3383-3388, 2007 11. Prevedello DM, Pouratian N, Sherman J, et al.: Management of Cushing's disease: outcome in patients with microadenoma detected on pituitary magnetic resonance imaging. J Neurosurg. 109(4):751-759, 2008 12. Semple PL, Laws ER Jr.: Complications in a contemporary series of patients who underwent transsphenoidal surgery for Cushing's disease. J Neurosurg. Aug 91(2):175-179, 1999

13. Semple PL, Vance ML, Findling J, Laws ER Jr.: Transsphenoidal surgery for Cushing's disease: outcome in patients with a normal magnetic resonance imaging scan. Neurosurgery. Mar;46(3):553-559, 2000

14. Sheehan JM, Lopes MB, Sheehan JP, Ellegala D, Webb KM, Laws ER Jr.: Results of transsphenoidal surgery for Cushing's disease in patients with no histologically confirmed tumor. Neurosurgery. 47(1):33-36, 2000 15. Starke RM, Reames DL, Chen CJ, Laws ER, Jane JA Jr: Endoscopic transsphenoidal surgery for Cushing disease: techniques, outcomes, and predictors of remission. Neurosurgery 72:240-247, 2013

16. Wagenmakers MA, Boogaarts HD, Roerink SH, Timmers HJ, Stikkelbroeck NM, Smit JW, et al.: Endoscopic transsphenoidal pituitary surgery: a good and safe primary treatment option for Cushing's disease, even in case of macroadenomas or invasive adenomas. Eur J Endocrinol 169:329-337, 2013

17. Yap LB, Turner HE, Adams CB, Wass JA: Undetectable postoperative cortisol does not always predict long-term remission in Cushing's disease: A single centre audit. Clin Endocrinol (Oxf) 56:25-31, 2002 